\title{
The American Research University and the Iowa Experience
}

\author{
Daniel Reed, Vice President for Research and Economic Development, \\ University of Iowa
}

W e humans are not particularly good predictors of change, particularly exponential change. We tend to extrapolate tomorrow from today, and in the near term, that is a safe and reasonable expedient. However, the pace of change is accelerating, with ever greater global connections and shifting social expectations. Thus, one would be surprised if these economic and social changes did not have equally profound implications for the role and function of the American research university - and they have.

The litany of public higher education woes -- rising tuition and student debt, declining state support, sequestration battered federal research budgets, mounting compliance and reporting burdens, escalating deferred maintenance concerns, and heightened political scrutiny - grows ever longer, framed by shifting societal expectations and a rising chorus of questions about educational value propositions. These public higher education issues must be considered in the broader socioeconomic context.

The lingering effects of the 2008 global recession, rising wage and income disparities in the United States, the European Union's uneasy and politically fraught economic confederation, and the unknowable true state of China's faltering economic growth all cast long shadows. Political instabilities, wars, sectarian and ethnic persecution and violence, and refugee flight define international political debates. Urbanization, global communications, talent mobility, and the global knowledge economy are reshaping social expectations.

Compounded by the consilience of globalization and the accelerating technological and scientific change, each year now brings disruptions that once defined generations. Universities, like our other organizational structures, are now challenged to adapt and respond, while preserving their core values.

\section{Telling the Future the Past}

As Figure 1 suggests, the history of U.S. higher education is one of punctuated equilibrium. The current structure of the American research university originated in the postbellum 1940s and 1950s. That is, it is a quite recent invention, with structures and programs created and funded in large part for economic benefit and national security. The Colonial Era. The nine "colonial colleges" were founded before the U.S. Revolutionary War and included all of the current Ivy League schools (except Cornell) plus Rutgers (then Queen's College) and William 


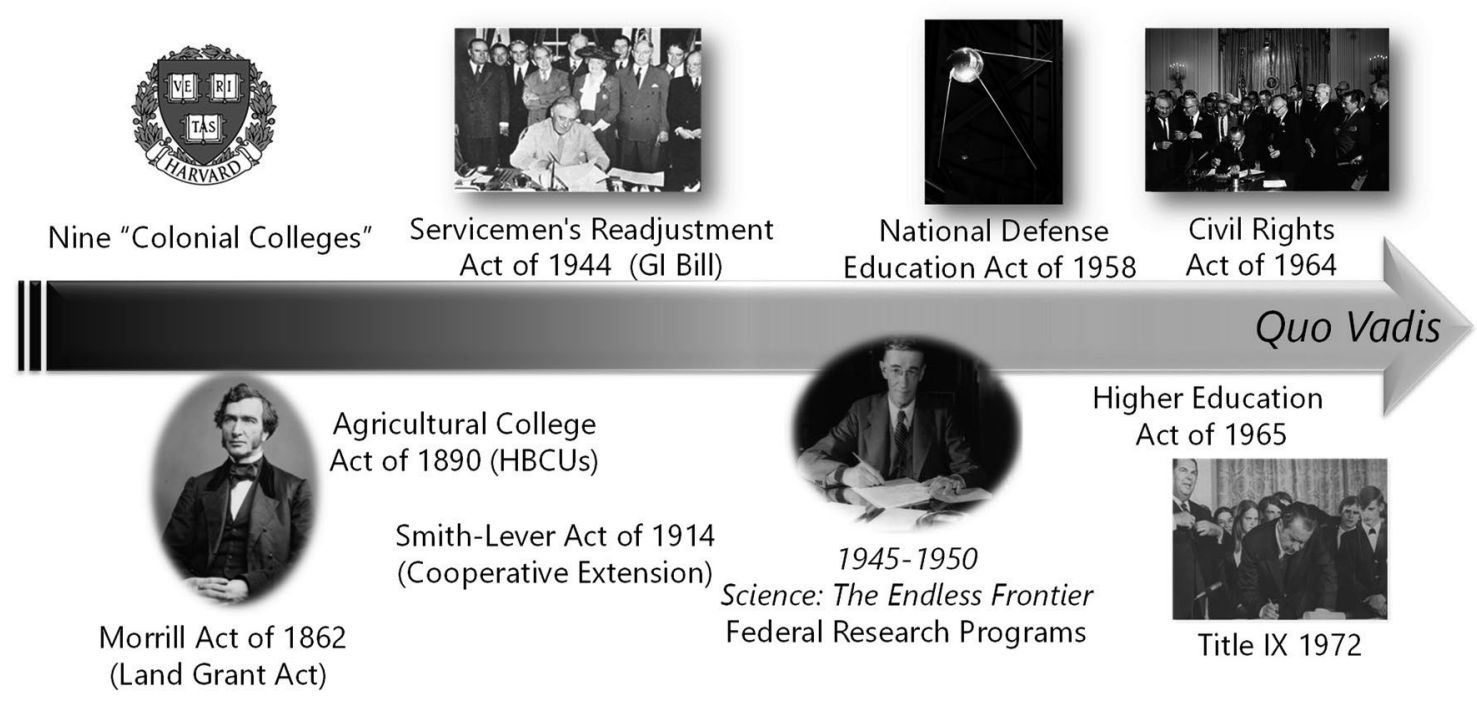

Figure 1 An abbreviated history of U.S. universities

and Mary. Harvard, the oldest, was founded in 1636 and was later named after clergyman John Harvard when he bequeathed his library and half of his estate to the college.

Many of these institutions were created to provide instruction to future clergy of various denominations. As Harvard noted in a 1643 brochure, the college's purpose was “To advance Learning and perpetuate it to Posterity; dreading to leave an illiterate Ministry to the Churches." Curricula were derived from the classic English model, itself an evolutionary variant of the medieval trivium (grammar, logic and rhetoric) and quadrivium (arithmetic, geometry, astronomy and music) with Latin and Greek fluency.

Following these early universities, and reflecting the growth and dispersion of the U.S. population, additional universities were created after the U.S. Revolutionary War, including the University of Virginia (founded by Thomas Jefferson) and the North Carolina at Chapel Hill. Jefferson argued that an educated popu- lace was necessary for the successful perpetuation of democracy, noting, "Whenever the people are well-informed, they can be trusted with their own government." Despite these secular extensions, the notion of education for practical pursuits was a decidedly secondary, often irrelevant consideration. This remained the status quo until the U.S. Civil War and the first major expansion of the Federal role in university life.

Land Grants and the Morrill Act. In 1862, Vermont Representative Justin Smith Morrill introduced a bill to grant each state 30,000 acres of public land for each Senator and Representative (based on the 1860 census). Proceeds from the land sales were to be invested in an endowment to support colleges of agriculture and mechanical arts in each of the states. In response, 37 states developed land-grant universities between 1862 and 1870. For the first time, practical training became a major focus of U.S. higher education. The land-grant concept was further expanded by the Smith-Lever Act of 
1914, which created the agricultural cooperative extension service.

Throughout the late nineteenth and early twentieth centuries, Congressional intent to provide economically useful information to the citizens of a largely agrarian society via on-site university and engagement programs was pointed and clear. The result was a striking transformation in agricultural practice among small farmers, and a personal awareness of university engagement. The land-grant institutions evolved from their early practice to encompass a broad-based educational mission that encouraged both the life of the mind and practical skills.

Vannevar Bush and World War II Science. World War II saw the dramatic rise of university-led engineering and science as technological enablers of defense capabilities. In his seminal July 1945 memorandum, Science, The Endless Frontier, Vannevar Bush argued cogently and persuasively that Federal investment in science was crucial, noting that "... without scientific progress no amount of achievement in other directions can insure our health, prosperity, and security as a nation in the modern world."

Bush had originally argued for a single science, integrated agency that included basic, defense, and medical research. After a tortuous political debate, the National Science Foundation (NSF) was created in 1950 to "promote the progress of science; to advance the national health, prosperity, and welfare; and to secure the national defense." Today, NSF is but one of a portfolio of funding agencies that includes both basic research and socalled mission agencies, including the
National Institutes of Health, the Department of Energy, and the Department of Defense.

The G.I. Bill. The Servicemen's Readjustment Act of 1944 - commonly known as the GI Bill of Rights - further transformed American higher education. It provided for college or vocational education for returning World War II veterans, a year of unemployment insurance and authorized loans for business starts and housing purchases. The economic and social effects of the G.I. Bill were profound.

Millions of degree seekers appeared on college campuses, forcing a dramatic and unprecedented expansion of college facilities and infrastructure. Enrollments often doubled in only a year or two. The influx of students also transformed college culture and expectations; a battlehardened veteran had rather different educational expectations than a naïve 18year-old scion of privilege. Over two million veterans received college educations in the war's aftermath, and the number of U.S. college degrees awarded doubled between 1940 and 1950 .

Sputnik and the NDEA. In response to the Soviet Union's 1957 launch of Sputnik I, the U.S. passed the 1958 National Defense Education Act (NDEA). The NDEA was intended to increase the number of trained scientists and engineers able to compete with the Soviet Union. As such, it included support for college loans, greater investment in science, mathematics, and foreign language instruction in primary and secondary schools, funding for graduate fellowships and vocational-technical training. In its 
own way, the NDEA was as transformative as the G.I. Bill, elevating Federal support for education generally and scientific education in particular as a national competitive priority during the Cold War. It changed the formula for Federal funding of university education and advanced science and engineering research within universities, rather than in separate institutes.

The astonishing intellectual and economic output from state and federal investment in higher education is perhaps unrivaled in history, and it has made the U.S. a magnet for the best and brightest minds on the planet. Against that backdrop, we now see declining state support and rising tuition costs, with selective student disenfranchisement. Concurrently, constrained research budgets have shattered the decades-old expectation that our best and brightest scholars and researchers would have the freedom and financial support to explore and discover.

\section{Quo Vadis: The Global Era}

What is the balance between intellectual inquiry and practical engagement? What is engaged scholarship? What are the "mechanical and industrial arts" for the $21^{\text {st }}$ century? What are verities, the intellectual and operational truths that now dance as shadows in Plato's Cave? What is the $21^{\text {st }}$ century public research university?

Any societal compact reification begins with identifying the irreducible core - the essential values that define academia. Quite clearly, these are unfettered discovery (original scholarship and research), transference (student education and training) and fulfillment (societal engagement and services). In each domain, the modern trivium explores the human condition, matter and the universe, and life and nature. Put another way, public research universities create new knowledge, transfer insights and ideas, and deliver solutions to societal problems

The American research university has changed radically and repeatedly over the past century. It emerged from the Cold War as a federally funded instrument of social change, economic competitiveness, and national security. There is no reason, indeed ample precedent to the contrary, to believe that it will not continue to evolve rapidly and radically. In this spirit, I humbly posit the following principles to guide our future, illustrated in Figure 2.

Accelerating Change. The pace of societal, technological, and economic change continues to accelerate. Universities must be equally nimble, recognizing that we are the citizen's instrument and must demonstrate our differential value to our constituents.

Knowledge and Skills Enhancement. A corollary of accelerating change is a shift in the episodic nature of university education. No longer will the knowledge and skills acquired at age 20 last a lifetime. They must be refreshed continually. University educational delivery must adapt accordingly, in recognition that a mid-career worker wants new knowledge and skills, not necessarily a degree.

Universal Franchise. In a knowledge world, advantage accrues to those regions that most effectively and efficiently attract, educate, and empower 


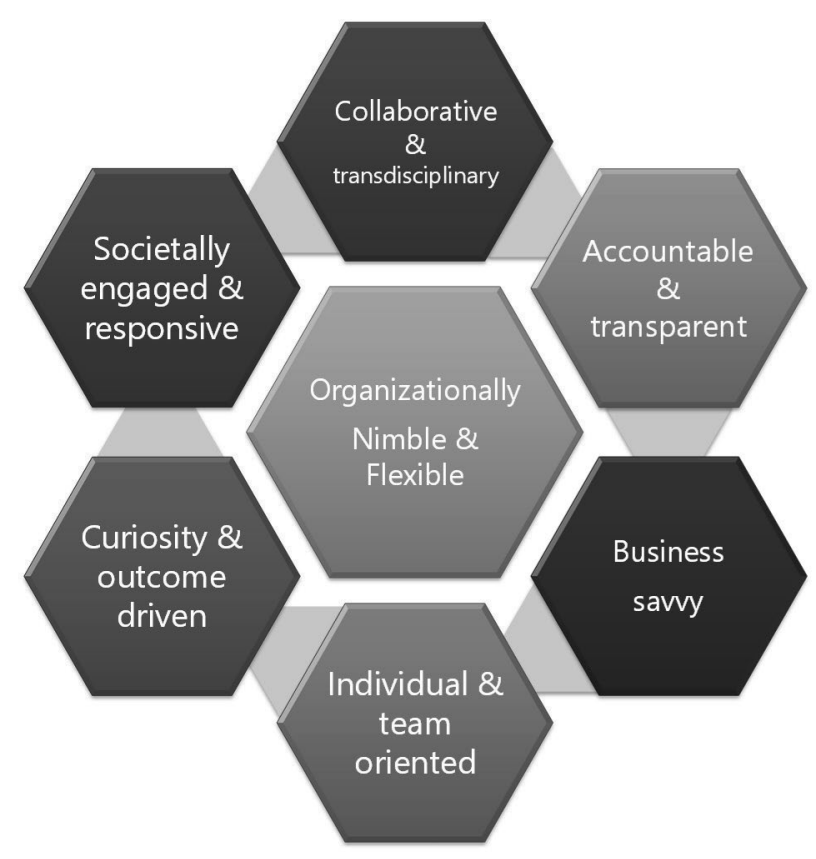

Figure 2 University futures and organizational change

\section{Organizational}

Nimbleness. As needs and opportunities shift, marshalling resources to adapt and respond, depends on flexibility and willingness to adjust organizational structures.

Disciplinary Fusion. Complex problems are rarely amenable to simplistic, isolated solutions, yet university structures reward individual excellence and depth and often punish collaborative exploration and breadth. Addressing

knowledge workers, without regard to ethnicity, national origin, socioeconomic status, sexual orientation, gender, religious beliefs, or politics. Talented people have always been and forever will be in short supply, but all of our citizens must be mobilized, not just the wealthiest or the most privileged. the biggest challenges of the $21^{\text {st }}$ century requires catholic, multidisciplinary teams - scholars, government leaders, and industry experts - who can share ideas, skills, and insights, without disciplinary silos.

Societal Engagement. The key lesson from university history is repeated

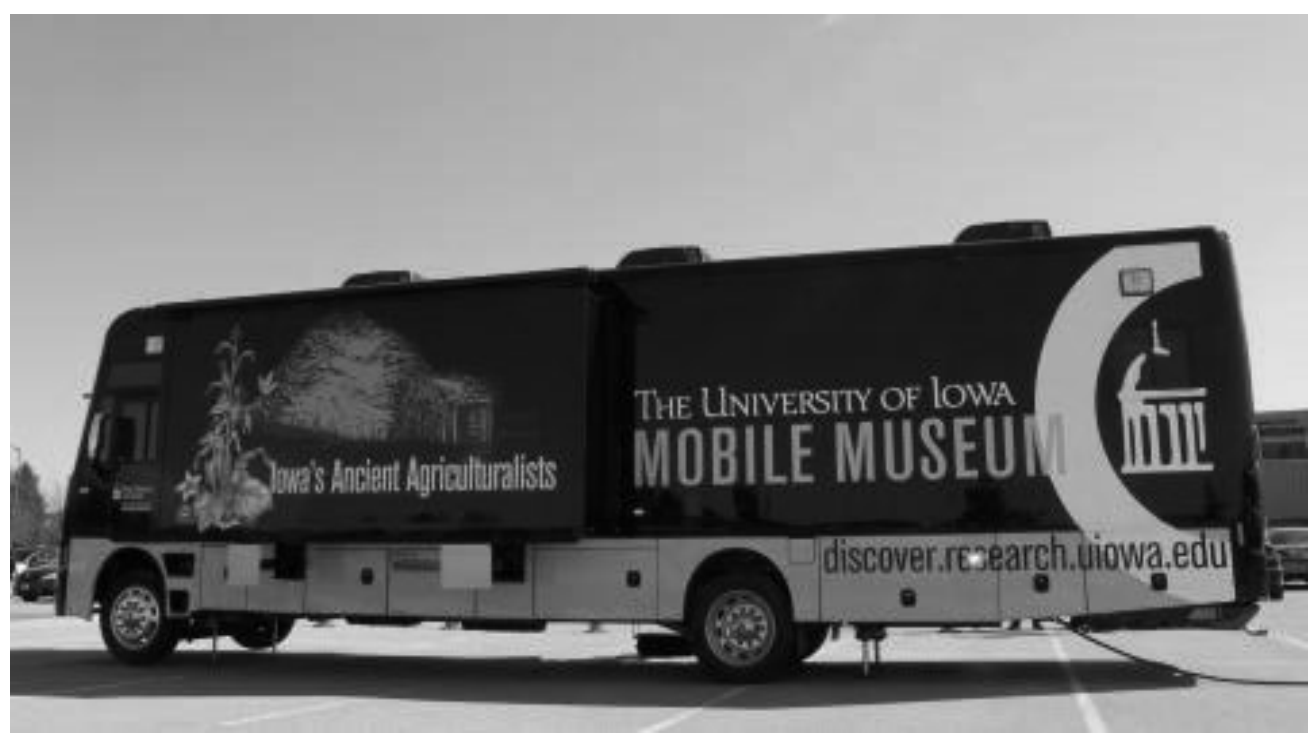

Figure 3 University of lowa Mobile Museum 
rebalancing of values - scholarship and knowledge acquisition as intrinsic goods and their application to practical problems and individual needs. Witness the transformative effects of the Morrill Act, the G.I. Bill, the NDEA and the Civil Rights Act. We must protect our core values while also engaging society to address pressing problems.

Global Perspective. We are each citizens of the world, affected by and affecting our global partners, despite our U.S. tendencies for isolationism. We must educate our students and our citizens for global citizenship, and give them an understanding of diverse cultures, languages, and processes.

\section{The Iowa Experience}

Reflecting shifting societal expectations, the University of Iowa has launched several initiatives to assist its faculty, staff and students in scholarship and research, technology transfer, economic development, and societal engagement. The following examples are just a few of these broad ranging initiatives.

Outreach and Mobile Museum. The University of Iowa Mobile Museum ${ }^{1}$ is a partnership among the University's $\mathrm{Mu}$ seum of Natural History and Old Capitol Museum, the Office of the State Archeologist, and the Office of the Vice-President for Research and Economic Development. Designed to allow annual replacement and refresh of its contents, the mobile museum includes displays on university research and scholarship as well as Iowa history, both natural and cultural. The 38-foot long RV, custom built by Winnebago Industries and shown in Figure 3, travels across Iowa, visiting schools, libraries, community events, and the state fair. This statewide outreach exposes K-12 students and Iowans to research breakthroughs and the university experience.

Research Metrics. Working with other members of the Committee on Institutional Cooperation (CIC) - the Big Ten plus the University of Chicago - the University of Iowa is analyzing its research expenditures to identify their direct and indirect impact on the state economy. The UMETRICS project is a CIC-led initiative that builds on insights and ideas from the federal STARMETRICS initiative. By showing where research funds are spent, county by county, as well as the number of faculty, staff, and students employed by research grants and contracts, the UMETRICS data provides clear and compelling evidence of the economic impact of research funding. Figure 4 illustrates county-by-county UMETRICS data.

Ideation Summits and Salons. Traditional academic scholarship and research reward deep specialization and expertise, an accelerating trend driven by the knowledge explosion and research funding competition. To encourage transdisciplinary scholarship and collaboration, the University of Iowa regularly invites hosts research summits that draw from the entire faculty. By facilitating discussion among scholars and researchers across the arts, humanities, social sci-

\footnotetext{
${ }^{1}$ University of lowa Mobile Museum, http://discover.research.uiowa.edu/mobile-museum
} 


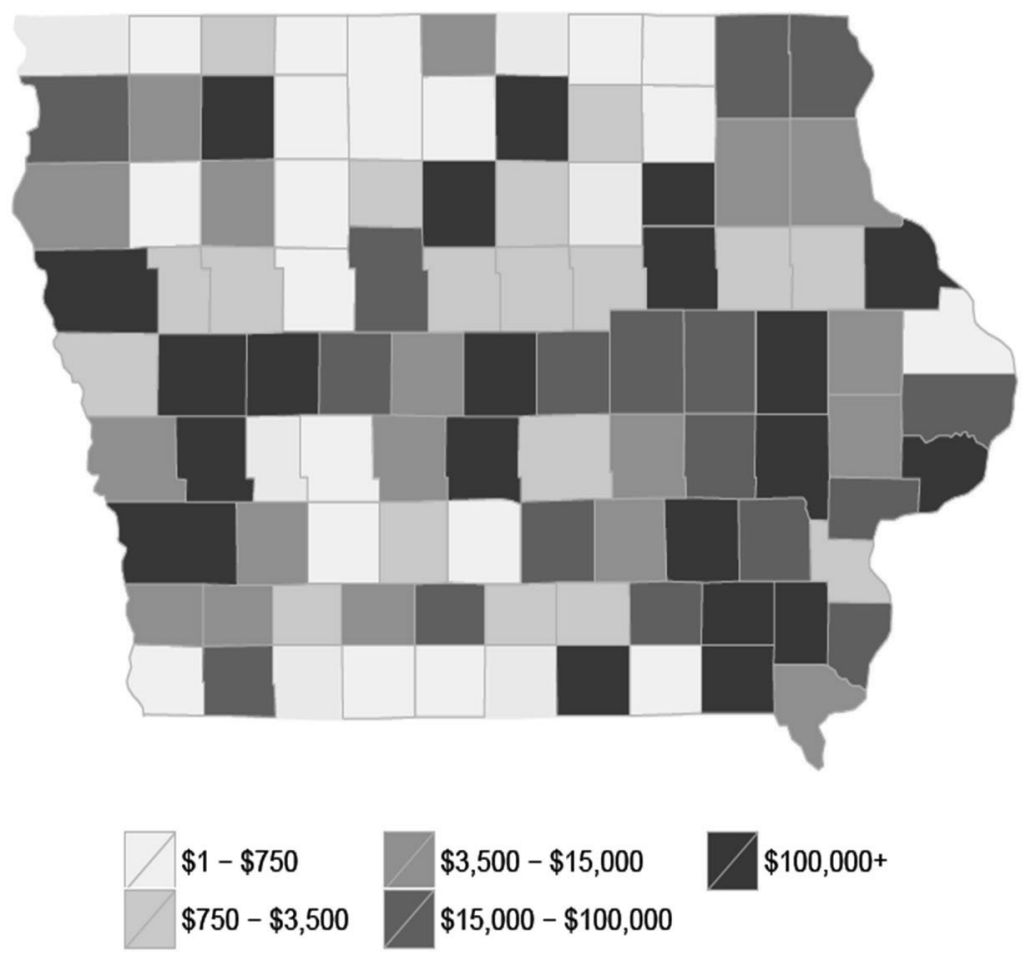

Figure 4 University of lowa UMETRICS Research Expenditures within lowa

ences, engineering, medicine and business, our goal is to foster broad collaborations.

In addition to ideation events, the University also hosts salon events ${ }^{2}$ to discuss challenging societal issues, drawing on the diverse perspectives and expertise of faculty. Example topics include the interplay of social norms, political power and biology on vaccinations and the spread of disease; evolving notions and expectations for privacy in the digital age; and political caucuses and communication in presidential elections.

\footnotetext{
2 University of lowa Salon Events, http://research.uiowa.edu/impact/news/ideas-intersectionsdinners-bring-together-scholars-researchers-and-art$\underline{\text { ists }}$
}

Internal Funding Initiatives. The University of Iowa's internal funding program $^{3}$ is structured to enable scholars and researchers to explore new directions, ones where they may not have the experience or data to be competitive for external funds. It also places high priority on rewarding high risk, multidisciplinary collaborations such as those that might emerge from ideation summits. In addition, these initiatives support acquisition of new instrumentation and facilities.

Faculty Media Training. The accelerating pace of scientific and technical discovery, with ever more frequent public policy implications, together with rising scrutiny of publicly funded research, makes it essential that we in academia communicate our work, its importance, and its relevance, in accessible and easily understandable ways. To aid faculty in communication, the University hosts seminars on the art of presentation, targeting both research and public audiences.

We also host cohorts of faculty for intensive media training, working with professional journalists and journalism faculty. These daylong seminars include the

\footnotetext{
${ }^{3}$ University of lowa Internal Funding Initiatives, http://research.uiowa.edu/researchers/find-funding/internal-funding-initiatives-ifi
} 
capture and critique of brief video descriptions of research, discussion about how to interact with journalists, and techniques for effective communication with lay audiences. Faculty members leave the seminar with a video succinctly describing their research and its broader relevance.

Faculty Fellows. The Office of the Vice President for Research and Economic Development (OVPR\&ED) hosts several faculty fellows. Each fellow spends approximately half of their time in the OVPR\&ED for a period of two-three years, working on targeted projects and serving as ambassadors to the campus community. In addition to gaining administrative insight and experience, each fellow brings faculty perspectives and ideas that help shape research and economic development policy.

Entrepreneurship and Economic Development. The University of Iowa's economic development mission is central to its role as a public research university. The economic development enterprise ${ }^{4}$ includes five interlocking elements:

- UIPartners, which works with small businesses across the state to help them remain competitive

- UIVentures, which assists faculty entrepreneurs with business planning and startup funding

- UIProtolabs, which helps companies and entrepreneurs across the state build prototypes of new projects, an essential step to demonstrating business viability

- UIRF, the University of Iowa Research Foundation, which licenses university inventions to both extant companies and entrepreneurial startups

\footnotetext{
${ }^{4}$ University of lowa Economic Development, http://research.uiowa.edu/business
}

- UIRP, the University of Iowa Research Park, which hosts startups and other businesses

- JPEC, the John Pappajohn Entrepreneurial Center, which trains students and faculty in business skills and Lean Launchpad business planning

Reaffirming the Dream

We face deep societal challenges - poverty, inequality, injustice, health and wellness, environmental sustainability, and economic uncertainty - and it is tempting to embrace a psychology of diminished expectations. However, we also have unprecedented opportunities, where the potential answers to age-old questions are tantalizingly close.

A great public research university is many things, derived from the three adjectives (great, public and research) and the noun (university):

- A tabula rasa for dreams

- A magnet for global talent

- A crucible of discovery and innovation

- An engine of the knowledge economy

- A framer of the crucial debates

- A transformative societal force

It is time to frame and engage the debate, to articulate our aspirations, and galvanize ourselves to collaborative action. Our future, and that of the country, depends on it.

Quo vadis? The future, of course.

\section{Acknowledgments}

My deep thanks to Susan Graham (UC Berkeley), Anita Jones (Virginia), Fred Schneider (Cornell) and others for insightful comments on early drafts of this essay. 